\title{
A Simplified Analysis to Predict the Fire Hazard of Primary Lithium Battery
}

\author{
Mingyi Chen ${ }^{1,2, *} \mathbb{C}$, Jiahao Liu ${ }^{3, *}$, Ouyang Dongxu ${ }^{4}$, Shuchao Cao ${ }^{5}$, Zhi Wang ${ }^{4}$ and Jian Wang ${ }^{4}$ \\ 1 School of the Environment and Safety Engineering, Jiangsu University, Zhenjiang 212013, Jiangsu, China \\ 2 Firefighting and Rescue Technology Key Laboratory of the Ministry of Public Security, China People's Police \\ University, Langfang 065000, Hebei, China \\ 3 College of Ocean Science and Engineering, Shanghai Maritime University, Shanghai 201306, China \\ 4 State Key Laboratory of Fire Science, University of Science and Technology of China, \\ Hefei 230026, Anhui, China; ouyang11@mail.ustc.edu.cn (O.D.); ustc14wz@mail.ustc.edu.cn (Z.W.); \\ wangj@ustc.edu.cn (J.W.) \\ 5 School of Automotive and Traffic Engineering, Jiangsu University, Zhenjiang 212013, Jiangsu, China; \\ sccao@ujs.edu.cn \\ * Correspondence: chenmy@ujs.edu.cn (M.C.); jiahao@shmtu.edu.cn (J.L.)
}

Received: 25 October 2018; Accepted: 16 November 2018; Published: 21 November 2018

\begin{abstract}
To better understand the fire risk of primary lithium batteries, the combustion properties of different numbers of primary lithium batteries were investigated experimentally in this work. Based on the $t^{2}$ fire principle and total heat release results from the experiments, a simplified analysis was developed to predict the fire hazard, and especially the heat release rate, of primary lithium batteries. By comparing the experiment and simulation results, the simulation line agrees well with the heat release rate curve based on the oxygen consumption measurements of a single primary lithium battery. When multiple batteries are burned, each battery ignites at different times throughout the process. The ignition time difference parameter is introduced into the simulation to achieve similar results as during multiple batteries combustion. These simulation curves conform well to the experimental curves, demonstrating that this heat release rate simulation analysis is suitable for application in batteries fires.
\end{abstract}

Keywords: lithium battery; heat release rate; $\mathrm{t}^{2}$ fire; simulation

\section{Introduction}

Lithium batteries are widely used in electronic products as they are highly energy-dense electrochemical cells. There are two kinds of lithium battery: the primary lithium battery, also called a lithium metal battery, and the secondary lithium battery, also called a lithium-ion battery. Primary lithium batteries have lithium metal or lithium compounds as the anode. By comparison, the lithium-ion battery is a member of the rechargeable battery family. Primary lithium batteries are commonly used in portable consumer electronic devices and in electric vehicles, ranging from full sized vehicles to radio controlled toys. The most widely used primary lithium battery is the lithium/manganese dioxide $\left(\mathrm{MnO}_{2}\right)$ couple. Lithium-ion batteries are common in consumer electronics. They are one of the most popular types of rechargeable battery for portable electronics, with one of the best energy densities, no memory effect, and only a slow loss of charge when not in use. In addition to consumer electronics, lithium-ion batteries are growing in popularity for military, electric vehicle, and aerospace applications. The mostly popular lithium-ion batteries are based on lithium cobalt oxide (LCO), lithium iron phosphate (LFP), lithium manganese oxide (LMO), and lithium nickel manganese cobalt oxide (NMC). 
All lithium batteries contain highly flammable organic solvents and potentially explosive components [1]. Many fire and explosion lithium battery accidents have occurred in the past and knowledge of appropriate fire protection agents has not kept pace with the industrial use of lithium batteries, which has grown substantially over the past few years [2,3]. Many past studies focused on the safety aspects of lithium batteries in relation to their components, such as electrode materials, the separator, the component of electrolyte, and its additives; to the structure of battery; and the manufacturing process [4-6]. Studies on other hazards of lithium batteries have been conducted on the overcharge, nail penetration, crush, and internal short circuit [7-9]. Fire behaviors of primary lithium and lithium-ion batteries have been more recently investigated $[10,11]$. The thermal runaway is thought to be the main cause of fire and explosion in lithium-ion batteries [12-14]. The burning of lithium batteries produces toxic gases such as $\mathrm{HF}, \mathrm{CO}$, and $\mathrm{SO}_{2}$, which threaten health $[15,16]$. Ribiere et al. studied the combustion of a single $2.9 \mathrm{Ah} \mathrm{LiMn}_{2} \mathrm{O}_{4}$ battery to investigate the process of battery fire, and found that the state of charge (SOC) significantly affected the burning behavior [17]. Ping et al. performed similar fire research to evaluate the safety of a large lithium-iron phosphate/graphite battery with 50 Ah capacity and significant fire hazards were also observed [18]. Larsson et al. conducted fire tests on commercial lithium iron phosphate batteries [19]. Fu et al. conducted an experimental study on the burning behaviors of 18,650 lithium-ion batteries, and evaluated the effects of SOC on burning behaviors of lithium-ion batteries [20]. According to their studies, SOC is the main factor affecting the thermal runaway and sustained fire. The SOC of a lithium-ion battery can significantly affect the burning behaviors, and it is generally thought that batteries with larger SOC have a greater ability to burn or explode [21-24]. Normally, higher SOC batteries produce higher heat release rate peaks and higher total HF emission than lower SOC batteries.

Batteries are rarely stored and transported as single batteries, and the burning behavior of a pile of multiple batteries can be drastically different from that of a single one. When lithium batteries catch fire, especially during air transport and storage, they can be extraordinarily hazardous. International Air Transport Association Dangerous Goods Regulations (IATA DGR) had introduced special rules about lithium battery transport for the prevention of fire and explosion. Federal Aviation Administration (FAA) had completed a series of tests to determine the flammability characteristics of primary lithium batteries and the dangers associated with shipping them in bulk on commercial transport category aircraft [25]. Scholars have conducted experimental and theoretical investigations to analyze the thermal runaway and fire behaviors of multiple lithium batteries. Feng et al. studied a three-dimensional (3D) thermal runaway propagation model for a large format lithium-ion battery module and presented four recommendations to postpone or prevent thermal runaway propagation [26,27]. Larsson predicted cell-to-cell fire propagation in a five lithium-ion battery pack by simulating the temperature distribution in neighboring cells, which is important for designing and validating safe systems [28]. Ouyang et al. found that the higher the number of batteries the worse the battery pack fire, and thermal failure appeared earlier for packs with more heaters [29]. Electric vehicles and plug-in hybrid electric vehicles use large batteries pack to store energy. The energy flows into the battery pack as it is charged, either from regenerative braking or from the grid, and discharges from the pack to power the vehicle. The charging and discharging current causes heating in the batteries; the higher the current the greater the heating effect. The performance of lithium battery is greatly impacted by its temperature, which can lead to thermal runaway. Special cooling systems may be required to prevent damage or even fire during charging and discharging [30-33].

In order to develop reliable fire protection strategies for the mass storage and transport of lithium batteries, more studies are needed to understand the fire behaviors of multiple lithium batteries. However, studying large-scale lithium battery fires with experiments is costly. A simulation method is needed to calculate the magnitude of fires for multiple large batteries in order to provide awareness and recommendations for safety protection. In this study, experiments and simulations were conducted to investigate the burning behaviors of different numbers of lithium batteries. The purpose was to 
establish a baseline set of analyses that characterize specific quantities of primary lithium batteries involved in an unsuppressed fire.

\section{Experimental Description}

The batteries used in this research are Panasonic (Osaka Prefecture, Japan) CR123A type lithium cells and Figure 1 shows the appearance and physical size parameters of the batteries (diameter $17 \mathrm{~mm}$, height $34.2 \mathrm{~mm}$ ). The specifications of the battery obtained from the product brochure were: nominal voltage $3 \mathrm{~V}$, nominal capacity $1550 \mathrm{mAh}$, and these batteries can be used from $-40^{\circ} \mathrm{C}$ to $85^{\circ} \mathrm{C}$. Panasonic CR123A is one of the most common lithium primary batteries using lithium as the anode and manganese dioxide $\left(\mathrm{MnO}_{2}\right)$ as the cathode. This battery is popular in cameras, game counters, photo equipment, medical equipment, tactical flashlights, and home security systems. This kind of battery has a wide operating temperature range, long shelf life, and is low cost. They are not normally used in large quantities together, but are often packaged together for transportation and storage. There is a large fire risk during these processes, especially during air transport.

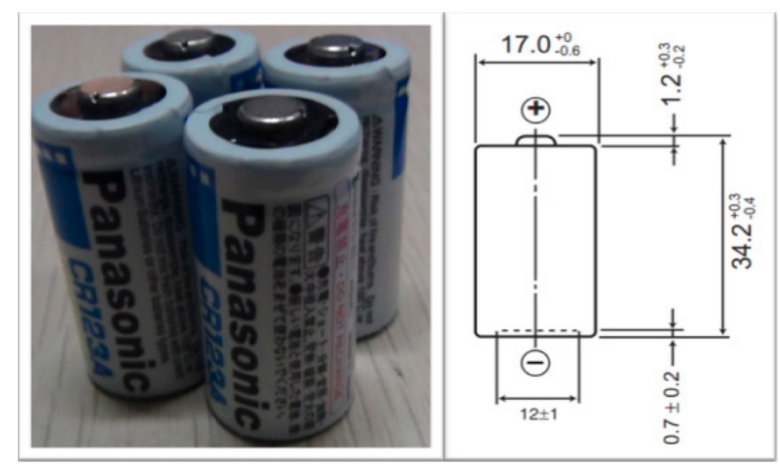

Figure 1. Panasonic CR123A primary lithium battery.

The most important parameter for defining fire hazard in this research is heat release rate (HRR). To cater to the current need, an in-situ calorimeter was constructed, which consisted of a burning chamber, an exhaust system, and a katharometer system. A detailed diagram of the in-situ calorimeter and experimental setup is shown in Figure 2. The dimensions of the burning chamber were $1.2 \times 1.2 \times 1.2 \mathrm{~m}$. The chamber had a $0.15 \mathrm{~m}$ gap at the bottom to allow the intake of fresh air. The gases were collected and removed by an exhaust pump with a volumetric flow rate of $0.18 \mathrm{~m}^{3} \mathrm{~s}^{-1}$. In general, heater choices for test apparatuses have included gas-fired panels, electric resistance heaters, and flames. Gas-fired panels or flames affect the measurement of HRR. In this study, a $2 \mathrm{~kW}$ electric radiation heater coil twined by the electric resistance was used and placed under the batteries at a vertical distance of $10 \mathrm{~mm}$. The batteries were placed on top of the wire net. The heat flux at the bottom of the battery specimen above the center of the heater was measured as $20 \pm 0.3 \mathrm{~kW} \mathrm{~m}^{-2}$. Under this thermal radiation, lithium batteries can be easily ignited. When the battery caught fire and released gases, the combustion gas escaped from the combustion chamber via the pipe and then was ejected outside by the exhaust pump. Part of the combustion gas was collected, sampled, filtered, and dried at the back of the exhaust pipe, and analyzed in a Servomex 4100 gas analyzer (Servomex, Egham, UK), which was designed to provide 3 simultaneous gas stream measurements of oxygen, carbon dioxide, and carbon monoxide. The HRR measurement by the in situ calorimeter is based on the oxygen consumption principle [34,35].

Six groups of experiments were designed to study fire scenarios and examine the effects of different numbers of batteries $(1,2,4,9,36$, and 100 batteries) on the primary lithium battery fire behavior. In this study, the samples were heated with a constant power using a heater. Therefore, the heating rate for every experimental configuration was the same. The simulation enabled the creation of a heat release rate curve for primary lithium batteries based on $\mathrm{t}^{2}$ fire model and MATLAB software (version 2014, 
MathWorks, Natick, MA, USA) mathematical curve construction. The simulation results were also compared with the experimental results to verify the rationality and accuracy of the simulation results.

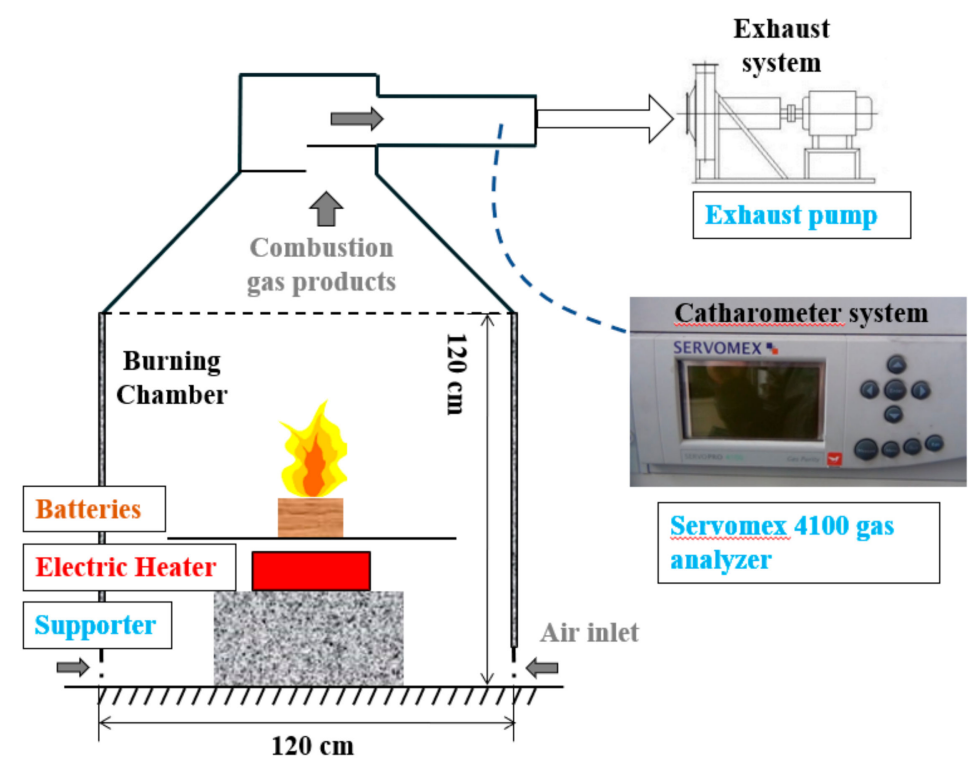

Figure 2. Diagram of in-situ calorimeter and experimental setup.

\section{Results and Discussion}

In 1980, Huggett introduced a method to estimate HRR based on oxygen consumption measurements [36]. After a combustion process has been completed, the HRR can be estimated by:

$$
\dot{q}=E\left(\dot{m}_{\mathrm{O}_{2}}^{0}-\dot{m}_{\mathrm{O}_{2}}\right)
$$

where $\dot{q}$ is the heat release rate, $\dot{m}_{\mathrm{O}_{2}}^{0}$ and $\dot{m}_{\mathrm{O}_{2}}$ are the mass flow rates of oxygen from the entrained air, and $E$ is the energy released per mass unit of $\mathrm{O}_{2}$ consumed for a given fuel. Huggett validated the constant net heat release per unit mass of oxygen consumed for organic solids and obtained an average value of $13.1 \mathrm{~kJ} \mathrm{~g}^{-1} \pm 5 \%$ for the constant. Considering incomplete combustion, the $\mathrm{CO}_{2}$ and $\mathrm{CO}$ consumption are also needed for correcting the HRR result.

The final form of the equation for HRR is then given by [37]:

$$
\dot{q}=\left[E \phi-\left(E_{C O}-E\right) \frac{1-\phi}{2} \frac{X_{C O}^{A}}{X_{O_{2}}^{A}}\right] \frac{M_{O_{2}}}{M_{a}} \frac{\dot{m}_{e}}{1+\phi(\alpha-1)}\left(1-X_{H_{2} O}^{0}\right) X_{O_{2}}^{A^{0}}
$$

with oxygen depletion factor:

$$
\phi=\frac{X_{\mathrm{O}_{2}}^{A^{0}}\left(1-X_{\mathrm{CO}_{2}}^{A}-X_{\mathrm{CO}}^{A}\right)-X_{\mathrm{O}_{2}}^{A}\left(1-X_{\mathrm{CO}_{2}}^{A^{0}}\right)}{\left(1-X_{\mathrm{O}_{2}}^{A}-X_{\mathrm{CO}_{2}}^{A}-X_{\mathrm{CO}}^{A}\right) X_{\mathrm{O}_{2}}^{A^{0}}}
$$

where $E=13.1 \mathrm{~kJ} / \mathrm{g}$ is the heat release per mass unit of oxygen consumed; $E_{\mathrm{CO}}=17.6 \mathrm{~kJ} / \mathrm{g}$ is the heat release for the conversion from $\mathrm{CO}$ to $\mathrm{CO}^{2} ; \alpha=1.105$ is the volumetric expansion factor; $M_{\mathrm{O}_{2}}=32 \mathrm{~g} / \mathrm{mol}$ and $M_{a}=29 \mathrm{~g} / \mathrm{mol}$ are the molecular weights of oxygen and air, respectively; $X_{\mathrm{O}_{2}}^{A^{0}}$ and $X_{\mathrm{CO}_{2}}^{A^{0}}$ are measured mole fraction of $\mathrm{O}_{2}$ and $\mathrm{CO}_{2}$, respectively; $X_{\mathrm{O}_{2}}^{A}, X_{\mathrm{CO}_{2}}^{A}$, and $X_{\mathrm{CO}}^{A}$ are the mole fraction of $\mathrm{O}_{2}, \mathrm{CO}_{2}$, and $\mathrm{CO}$ in the incoming air, respectively; and $\mathrm{X}_{\mathrm{H}_{2} \mathrm{O}}^{0}$ is the mole fraction of water in the incoming air.

According to the oxygen consumption principle and experimental method, the HRR of a lithium battery can be obtained. Figure 3 shows the HRR data of one Panasonic CR123A battery. The maximum 
HRR value is $2.51 \mathrm{~kW}$. The energy is released within a very short time, which may entail the potential risk of explosion. The integration of the HRR curve is the totally released heat (THR) of the lithium batteries fire.

$$
\mathrm{THR}=\int_{0}^{\mathrm{t}} \dot{q}(\tau) \mathrm{d} \tau
$$

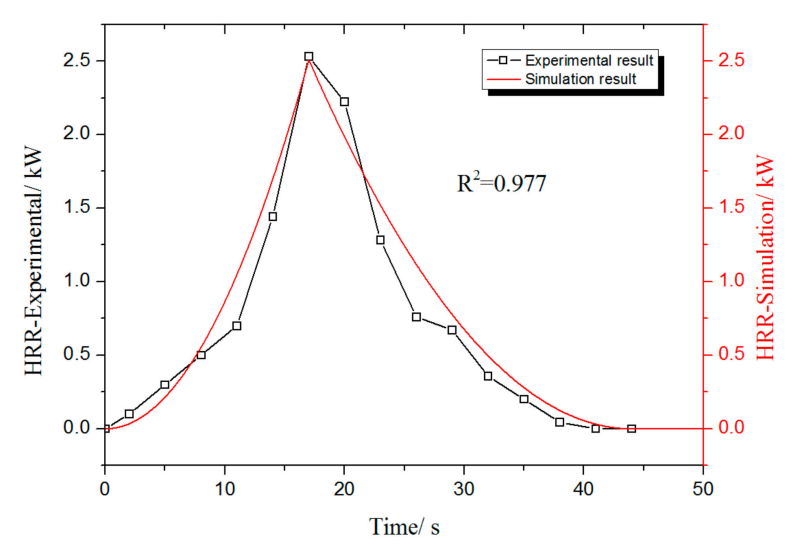

Figure 3. Experimental and simulated heat release rate (HRR) result for single battery.

The detailed maximum HRR and THR data are shown in Table 1. The discussed methodology to create the designed lithium battery fire and criteria for selection of input data are, at best, based on a generalization of fire experimental data and statistics. Performing an analysis to determine a plausible designed lithium battery fire scenario for predicting fire growth was our objective. The $t^{2}$ fire model was used to create the designed lithium battery fire, and the required data were based on the experiment results in Table 1.

Table 1. Experimental and simulation values for single battery. HRR denotes heat release rate.

\begin{tabular}{|c|c|c|c|c|}
\hline & \multicolumn{2}{|c|}{ Time (s) } & \multirow{2}{*}{ Maximum HRR (kW) } & \multirow{2}{*}{ Heat (kJ) } \\
\hline & $t_{1}$ & $t_{2}$ & & \\
\hline Experiment & 17 & 44 & 2.51 & 32.4 \\
\hline Simulation & 17 & 44 & 2.51 & 33.6 \\
\hline
\end{tabular}

Experimental research has shown that the HRR changes with time. For a wide range of fires, the fire growth can be accurately represented with a power law relation:

$$
\dot{q}=b \cdot t^{2}
$$

where $\dot{q}$ is the heat release rate of the fire, $b$ is the fire intensity coefficient, and $t$ is time. National Institute of Standards and Technology (NIST) developed this model that is used in Consolidate Fire and Smoke Transport (CFAST), which is simulation software for fire and smoke spreading in multi-room buildings [38]. According to the combustion behavior and the HRR curve, lithium battery fires are quite fast, involving a jetting fuel process, which is suitable for the $t^{2}$ fire model. The complete $t^{2}$ fire model of a specific fire can be built by presetting the fire growth phase, maximum heat release rate, and fire attenuation phase. Its mathematical description is:

$$
\begin{array}{cc}
\dot{Q}=b_{1} t^{2} & 0 \leq t \leq t_{1} \\
\dot{Q}=\dot{Q}_{\text {max }} & t=t_{1} \\
\dot{Q}=b_{2}\left(t-t_{2}\right)^{2} & t_{1} \leq t \leq t_{2}
\end{array}
$$


where $b_{1}$ is the fire growth rate coefficient, $\dot{Q}_{\max }$ is the maximum HRR, $b_{2}$ is the fire attenuation rate coefficient, $t_{1}$ is the maximum HRR time, and $t_{2}$ is the fire end time. The fire of single lithium battery was designed according to the specific $t_{1}, t_{2}$, and maximum HRR values listed in Table 1 .

The designed fire for one lithium battery is shown in Figure 3. The designed lithium battery fire data were compared with the experimental result with a correlation coefficient of 0.977 , which supports a good statistical relationships between the two data values. The designed lithium battery fire was assumed the same $t_{1}$, maximum HRR, and $t_{2}$. The difference was the calculated released heat, which was $32.4 \mathrm{~kJ}$ for the experiment and $33.6 \mathrm{~kJ}$ for the designed simulation, and the margin of error was about $3.7 \%$. The simulation can be used as a fundamental element for fire prediction of multiple batteries and bundled packs.

The energy released in the combustion process should increase in proportion to the amount of fuel, which has a certain combustion efficiency. Unlike normal combustion, lithium battery fire is a fast and jetting fuel process. The released energy is correlated with the complete degree of the combustion. Previous discussion indicated that the energy released is not proportionally related to the battery numbers $(n)$ of a simple cell [10]. It can be assumed that an exponential relationship between thermal energy released and the number of batteries is:

$$
Q_{n}=Q_{1} \cdot n^{a}
$$

where $n$ is the battery number, $Q_{n}$ is the energy released from $n$ batteries, and $Q_{1}$ is the energy released from one battery. The fitting result by Chen et al. was $Q_{1}=31.77 \mathrm{~kJ}, a=1.26$, and fitting coefficient of 0 . 997. The equation should be added into the simulation of a multiple lithium battery fire. The most difficult problem is that the ignition time of each battery in the bundle is random. Even in the same external environment and with the same heating power, batteries do not always ignite at the same time. We observed that the time of ignition was quite random or varied significantly under the same external heating condition. The non-simultaneous ignition of batteries resulted in differences in heat release rate data. Figure 4 shows the two different experiment results of two batteries under the same heating condition. The two batteries ignited at the same time in Case A and separately in Case B. The time gap in Case B was about $19 \mathrm{~s}$. Given the sporadic ignition of individual batteries in a multi-cell bundle, the maximum heat release rate of the bundle is not equal to the product of the single battery maximum heat release rate multiplied by the number of batteries in the bundle. The time gap in ignitions should be considered in the mathematical calculation process. A time random variable could be added into the HRR simulation for bundled batteries. The ignition gap of two batteries cannot exceed $30 \mathrm{~s}$ according to the experiment results:

$$
0 \leq T_{\text {ignition gap }} \leq 30
$$

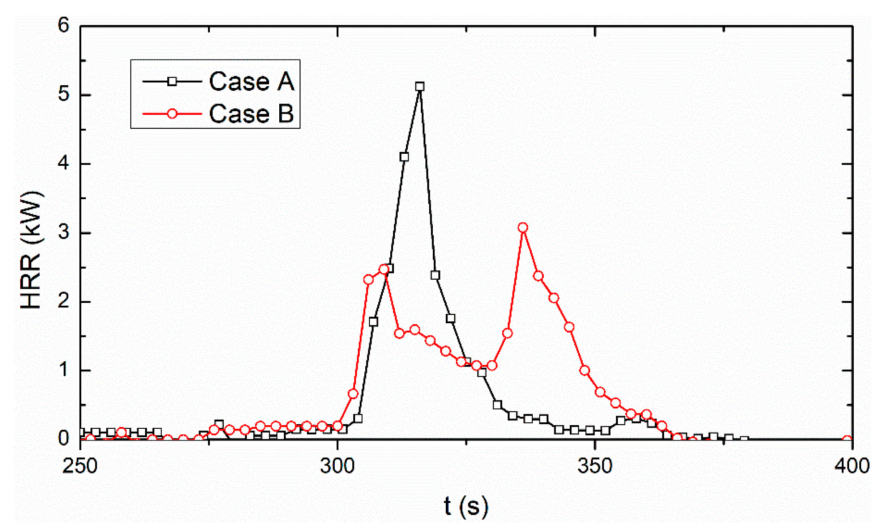

Figure 4. Heat release rate (HRR) experimental results of the ignition two batteries. 
Considering the exponential relationship of energy, Equation (5) can be written as:

$$
\dot{q}_{n}=n^{a} \cdot b \cdot t^{2}
$$

By introducing a time variable and combining the $t^{2}$ fire model and the heat release rate growth model, the HRRs of one, two, four, and nine batteries were simulated and compared with the experimental results, as shown in Figure 5. The ignition time gap was random so the HRR curve was not unique. The battery combustion curve in the experiment was also not unique. The calculation results were close to the experimental results under the same ignition time gap condition. According to the results, the overall simulation trend was close to the experimental results, and the values of maximum HRR and total heat release (THR) were close to each other, as shown in Table 2. Therefore, this simulation can be used as a preliminary analysis to simulate the scale of a lithium battery fire, providing a reference for the simulation of foreseeable disasters.
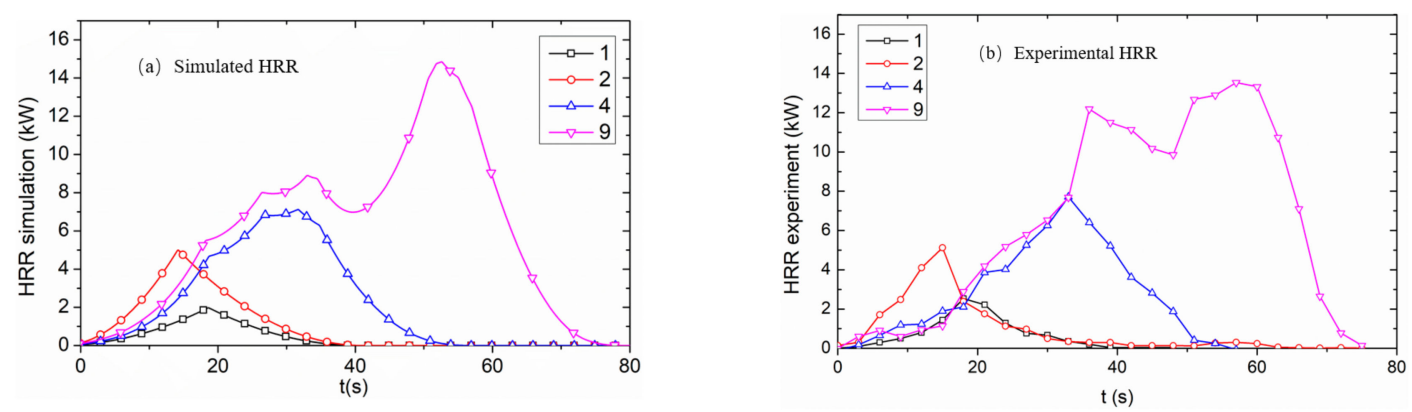

Figure 5. (a) Simulated and (b) experimental HRR results of one, two, four, and nine batteries.

Table 2. Maximum HRR and THR of experimental and simulated one, two, four, and nine batteries.

\begin{tabular}{cccccc}
\hline \multirow{2}{*}{$\begin{array}{c}\text { No. of } \\
\text { Batteries }\end{array}$} & \multicolumn{2}{c}{ Maximum HRR (kW) } & \multicolumn{2}{c}{ THR (kJ) } & \multirow{2}{*}{$\begin{array}{c}\text { Difference in } \\
\text { THR }\end{array}$} \\
\cline { 2 - 5 } & Experiment & Simulation & Experiment & Simulation & $3.7 \%$ \\
1 & 2.51 & 2.51 & 32.4 & 33.6 & $7.4 \%$ \\
2 & 5.12 & 5 & 68.5 & 73.6 & $1.4 \%$ \\
4 & 7.71 & 7.12 & 164.6 & 166.9 & $-6.3 \%$ \\
9 & 13.53 & 14.86 & 495.2 & 463.8 & \\
\hline
\end{tabular}

When a large number of batteries burned, as the combustion scale increased, several batteries ignited at the same time. This process is more likely to occur after the flame increases. It is necessary to assume that several batteries ignite simultaneously at a certain time when simulating a large number of batteries burning. The ignition gap at this time is not simply between two batteries, but the ignition interval of the battery pack. Applying the simulation analysis to a fire with more batteries, the comparison results of a $6 \times 6$ and $10 \times 10$ test are shown in Figure 6 . The changing trends in the simulation curves are consistent with the experimental curves. Obtained by the figure, the simulation THR data from $6 \times 6$ and $10 \times 10$ were calculated as $2802 \mathrm{~kJ}$ and 10,388 kJ, respectively. The energies of the three groups of $6 \times 6$ experiments were $2925 \mathrm{~kJ}, 2800 \mathrm{~kJ}$, and $2834 \mathrm{~kJ}$; and 10,080 kJ, $9985 \mathrm{~kJ}$, and $10,290 \mathrm{~kJ}$ for $10 \times 10$ tests. These results feasibly aligned with the fitting line. There was a small difference in reaction time between simulation and experimental results for the $10 \times 10$ test. The reason for this difference is that both the reaction time of the experiment and simulation were not a fixed value. These simulation curves conformed well to the experimental ones. As a result, this HRR simulation analysis is suitable for simulation of CR123A battery fires. 


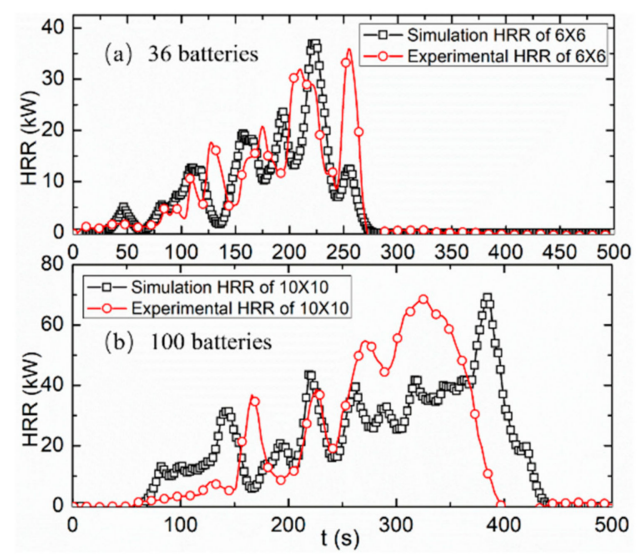

Figure 6. Comparison results of fires of 36 (a) and 100 (b) lithium-ion batteries.

Based on the analysis methodology, primary lithium battery fire could be predicted. Firstly, the curve of the HRR for a single primary lithium battery was plotted. The curve provides a simplified analysis to create the heat release rate curve of a primary lithium battery based on $\mathrm{t}^{2}$ fire model in Equations (5)-(8) and using MATLAB software for mathematical curve construction. The required data for $\mathrm{t}^{2}$ fire were obtained experimentally (Table 1). Secondly, the individual curves of the single battery were integrated into one curve for predicting the HRR curve of a primary lithium battery pack; that is, the combustion of each battery in the pack was added up to form a whole pack fire. The most important factors for predicting the HRR curve of a primary lithium battery pack are the HRR growth model in Equation (11) and the hypothetical time horizon for sporadic ignition of individual batteries in a multi-cell bundle in Equation (10). The methodology to select the input data was based on a generalization of fire experiment data and statistics. Thirdly, the HRR curve of a specific number of primary lithium battery packs can be plotted within a given range. The drawn curve will be different from the experimental curve mainly because of the uncertainty in battery ignition time in the reality.

\section{Conclusions}

The combustion properties of 1,2, 4, 9, 36, and 100 primary lithium batteries were experimentally examined in this paper. Based on the $t^{2}$ fire principle and total heat release results from the experiments, a simplified analysis was further developed to predict the fire hazard, and especially the heat release rate of primary lithium batteries. An exponential relationship between thermal energy released and the number of batteries was added into the simulation of a fire of multiple lithium batteries. The most difficult problem for simulation was that the ignition time of each battery in the bundle is random. Even in the same external environment and under the same heating power, the batteries did not always ignite at the same time. The ignition time difference parameter was introduced into the simulation to achieve similar results to the heat release rate of the multiple battery combustion. By comparing the experimental and simulation results, the heat release rate curves based on the oxygen consumption measurements of 1, 2, 4, 9, 36, and 100 primary lithium batteries agreed well with the simulation. The overall trend and curve shape were similar to the experimental results, and the values of maximum HRR and THR were close to each other.

The experiments and simulations with different numbers of batteries in the current study provide some insights into the fire hazards of primary lithium batteries and indicate the possibility of predicting their heat release rate with a more accurate and simplified model. This prediction analysis is applicable to primary lithium batteries that are smaller than or equal to the dimensions used in this study. The results cannot be directly extrapolated to larger or even industrial scale batteries unless further validation is conducted.

Author Contributions: Conceptualization, C.M. and L.J.; Methodology, C.M., O.D. and W.J.; Investigation, C.S. and W.Z.; Writing-Review \& Editing, C.M., L.J. and O.D. 
Funding: This research was supported by the National Key Research and Development Program of China (2018YFC0808600), the opening fund of Key Laboratory of Firefighting and Rescue Technology, Ministry of Public Security (KF201801), Programs of Senior Talent Foundation of Jiangsu University (17JDG036), and the Shanghai Sailing Program (18YF1409600).

Conflicts of Interest: The authors declare no conflict of interest.

\section{References}

1. Nishio, K. PRIMARY BATTERIES-NONAQUEOUS SYSTEMS I Lithium-Manganese Dioxide; Elsevier: Kyoto, Japan, 2009.

2. Tarascon, J.M.; Armand, M. Issues and challenges facing rechargeable lithium batteries. Nature 2001, 414, 359-367. [CrossRef] [PubMed]

3. Ruiz, V.; Pfrang, A.; Kriston, A.; Omar, N.; Bossche, P.V.D.; Boon-Brett, L. A review of international abuse testing standards and regulations for lithium ion batteries in electric and hybrid electric vehicles. Renew. Sustain. Energy Rev. 2017, 81, 1427-1452. [CrossRef]

4. Farrington, M.D. Safety of lithium batteries in transportation. J. Power Sources 2001, 96, 260-265. [CrossRef]

5. Lisbona, D.; Snee, T. A review of hazards associated with primary lithium and lithium-ion batteries. Process Saf. Environ. Prot. 2011, 89, 434-442. [CrossRef]

6. Selman, J.R.; Al Hallaj, S.; Uchida, I.; Hirano, Y. Cooperative reserach on safety fundamentals of lithium batteries. Power Sources 2001, 97-98, 726-732. [CrossRef]

7. Fan, J. Studies of 18650 cylindrical cells made with doped $\mathrm{LiNiO}_{2}$ positive electrodes for military applications. Power Sources 2004, 138, 288-293. [CrossRef]

8. Underwriters Laboratories Inc. UL Safety Issues for Lithium-Ion Batteries. 2005. Available online: www.ul. com (accessed on 21 November 2018).

9. Finegan, D.P.; Scheel, M.; Robinson, J.B.; Tjaden, B.; Di Michiel, M.; Hinds, G.; Brett, D.J.; Shearing, P.R. Investigating lithium-ion battery materials during overcharge-induced thermal runaway: An operando and multi-scale X-ray CT study. Phys. Chem. Chem. Phys. 2016, 18, 30913-30919. [CrossRef] [PubMed]

10. Chen, M.; He, Y.; De Zhou, C.; Richard, Y.; Wang, J. Experimental Study on the Combustion Characteristics of Primary Lithium Batteries Fire. Fire Technol. 2016, 52, 365-385. [CrossRef]

11. Chen, M.; Liu, J.; Lin, X.; Huang, Q.; Yuen, R.; Wang, J. Combustion characteristics of primary lithium battery at two altitudes. J. Therm. Anal. Calor. 2016, 124, 865-870. [CrossRef]

12. Wang, Q.; Ping, P.; Zhao, X.; Chu, G.; Sun, J.; Chen, C. Thermal runaway caused fire and explosion of lithium ion battery. J. Power Sources 2012, 208, 210-224. [CrossRef]

13. Anderson, J.; Larsson, F.; Andersson, P.; Mellander, B.-E. Fire spread due to thermal runaway in a lithium-ion battery cell. In Proceedings of the Fires in Vehicles (FIVE) 2014 Conference Proceedings, Berlin, Germany, 1-2 October 2014; pp. 267-270.

14. Larsson, F.; Bertilsson, S.; Furlani, M.; Albinsson, I.; Mellander, B.E. Gas explosions and thermal runaways during external heating abuse of commercial lithium-ion graphite- $\mathrm{LiCoO}_{2}$ cells at different levels of ageing. J. Power Sources 2018, 373, 220-231. [CrossRef]

15. Larsson, F.; Andersson, P.; Blomqvist, P.; Mellander, B.E. Toxic fluoride gas emissions from lithium-ion battery fires. Sci. Rep. 2017, 7, 10018. [CrossRef] [PubMed]

16. Huang, P.; Wang, Q.; Li, K.; Ping, P.; Sun, J. The combustion behavior of large scale lithium titanate battery. Sci. Rep. 2015, 5, 7788. [CrossRef] [PubMed]

17. Ribière, P.; Grugeon, S.; Morcrette, M.; Boyanov, S.; Laruelle, S.; Marlair, G. Investigation on the fire-induced hazards of Li-ion battery cells by fire calorimetry. Energy Environ. Sci. 2012, 5, 5271-5280. [CrossRef]

18. Ping, P.; Wang, Q.; Huang, P.; Li, K.; Sun, J.; Kong, D.; Chen, C. Study of the fire behavior of high-energy lithium-ion batteries with full-scale burning test. J. Power Sources 2015, 285, 80-89. [CrossRef]

19. Larsson, F.; Andersson, P.; Blomqvist, P.; Lorén, A.; Mellander, B.E. Characteristics of lithium-ion batteries during fire tests. J. Power Sources 2014, 271, 414-420. [CrossRef]

20. Fu, Y.; Lu, S.; Li, K.; Liu, C.; Cheng, X.; Zhang, H. An experimental study on burning behaviors of 18650 lithium ion batteries using a cone calorimeter. J. Power Sources 2015, 273, 216-222. [CrossRef]

21. Wang, Q.; Huang, P.; Ping, P.; Du, Y.; Li, K.; Sun, J. Combustion behavior of lithium iron phosphate battery induced by external heat radiation. J. Loss Prev. Process Ind. 2017, 49, 961-969. [CrossRef] 
22. Mao, B.; Chen, H.; Cui, Z.; Wu, T.; Wang, Q. Failure mechanism of the lithium ion battery during nail penetration. Int. J. Heat Mass Transfer 2018, 122, 1103-1115. [CrossRef]

23. Chen, M.; Liu, J.; He, Y.; Yuen, R.; Wang, J. Study of the fire hazards of lithium-ion batteries at different pressures. Appl. Therm. Eng. 2017, 125, 1061-1074. [CrossRef]

24. Chen, M.; Zhou, D.; Chen, X.; Zhang, W.; Liu, J.; Yuen, R.; Wang, J. Investigation on the thermal hazards of 18650 lithium ion batteries by fire calorimeter. J. Therm. Anal. Calor. 2015, 122, 755-763. [CrossRef]

25. Webster, H. Flammability Assessment of Bulk-Packed, Nonrechargeable Lithium Primary Batteries in Transport Category Aircraft; DOT/FAA/AR-04/26; Federal Aviation Administration: Washington, D.C., USA, 2004.

26. Feng, X.; Lu, L.; Ouyang, M.; Li, J.; He, X. A 3D thermal runaway propagation model for a large format lithium ion battery module. Energy 2016, 115, 194-208. [CrossRef]

27. Feng, X.; Sun, J.; Ouyang, M.; Wang, F.; He, X.; Lu, L.; Peng, H. Characterization of penetration induced thermal runaway propagation process within a large format lithium ion battery module. J. Power Sources 2015, 275, 261-273. [CrossRef]

28. Larsson, F.; Anderson, J.; Andersson, P.; Mellander, B.E. Thermal modelling of cell-to-cell fire propagation and cascading thermal runaway failure effects for lithium-ion battery cells and modules using fire walls. J. Electrochem. Soc. 2016, 163, A2854-A2865. [CrossRef]

29. Ouyang, D.; Liu, J.; Chen, M.; Weng, J.; Wang, J. An Experimental Study on the Thermal Failure Propagation in Lithium-Ion Battery Pack. J. Electrochem. Soc. 2018, 165, A2184-A2193. [CrossRef]

30. Jarrett, A.; Kim, I.Y. Design optimization of electric vehicle battery cooling plates for thermal performance. J. Power Sources 2011, 196, 10359-10368. [CrossRef]

31. Panchal, S.; Dincer, I.; Agelin-Chaab, M.; Fraser, R.; Fowler, M. Experimental and theoretical investigations of heat generation rates for a water cooled $\mathrm{LiFePO}_{4}$ battery. Int. J. Heat Mass Transfer 2016, 101, 1093-1102. [CrossRef]

32. Tian, Z.; Gan, W.; Zhang, X.; Gu, B.; Yang, L. Investigation on an integrated thermal management system with battery cooling and motor waste heat recovery for electric vehicle. Appl. Therm. Eng. 2018, 136, 16-27. [CrossRef]

33. Al-Zareer, M.; Dincer, I.; Rosen, M.A. Heat and mass transfer modeling and assessment of a new battery cooling system. Int. J. Heat Mass Transfer 2018, 126, 765-778. [CrossRef]

34. ISO. 9705, Fire Tests_Full Scale Room Test for Surface Products; International Organization for Standardization: Geneva, Switzerland, 1990.

35. ISO. ISO 5660-1: Reaction-to-Fire Tests-Heat Release, Smoke Production and Mass Loss Rate-Part 1: Heat Release Rate (Cone Calorimeter Method). 2002. Available online: www.iso.org (accessed on 21 November 2018).

36. Huggett, C. Estimation of rate of heat release by means of oxygen consumption measurements. Fire Mater 1980, 4, 61-65. [CrossRef]

37. Janssens, M.L. Measuring rate of heat release by oxygen consumption. Fire Technol. 1991, 27, $234-249$. [CrossRef]

38. Peacock, R.D.; Jones, W.; Reneke, P.; Forney, G. CFAST—Consolidated Model of Fire Growth and Smoke Transport (Version 6) User's Guide; NIST Special Publication: Gaithersburg, MD, USA, 2005; Volume 1041.

(C) 2018 by the authors. Licensee MDPI, Basel, Switzerland. This article is an open access article distributed under the terms and conditions of the Creative Commons Attribution (CC BY) license (http:/ / creativecommons.org/licenses/by/4.0/). 